kept from falling together by its use. The writer seems to be wholly ignorant of the researches laid by myself before the Royal Society, proving that the Eustachian tube is opened only during the act of swallowing, and by the muscles of the Eustachian tube. He may convince himself of the truth of this statement by closing his own nose, and then, while attempting an inspiration through the nose, he shall swallow some saliva. He will at once feel a sense of pressure in each ear, caused by the withdrawal of some air from each tympanum, and that sense of pressure remains until the act of swallowing is again performed, and air is thus readmitted.

7. The writer concludes his paper by stating that in cases where the tympanic membrane is ruptured, his habitual "treatment of the tube, with the object of restoring its passage to as normal a condition as possible, is by means of bougies, often combined with injections of astringents and nitrate of silver." Having just placed before the MedicoChirurgical Society a paper, in which I have endeavoured to connect the several pathological states associated with perforate membrana tympani and disease of the chain of bones, with their treatment, I shall now simply state that, as Dr. Weber has not succeeded in rendering the Eustachian tube patent in any one case of perforate membrana tympani, he can thereby have exercised no influence for good or evil upon the deafness attending certain cases of perforate membrana tympani. Any improvement to the hearing following the use of bougies and air-douches is to be explained by a knowledge of the reflex action of the muscles of the tympanum, and by the fact of the removal of mucus from the chain of bones, the latter being thus permitted to gain more or less a state of continuity.

Such is the real meaning of Dr. Weber's paper when it is carefully examined under the light of anatomy, physiology, and pathology.

I need not offer an apology for this public criticism of Dr. Weber's paper. Engaged, as I have been, in the study of the diseases of the ear during many years, I have watched the progress of this branch of surgery with deep interest, feeling conscious that, by earnest, honest, persevering labour, it will take a rank second to that of no other department of medical science; and this not only on account of its own intrinsic importance, but also on account of the light it may throw on pathology generally. And I must add, that when I see the medical profession gradually taking an interest in the subject of aural surgery, when I see our large hospitals establishing departments for teaching it, when I see hospital reports and our best Societies publishing papers on Aural Pathology, and that a journal has been established especially devoted to the elucidation of ear diseases, and when I know that scientific workers on the subject in all parts of Europe and America, many of them having studied here, keep their eyes closely scanning the labours of Englishmen and the writings in English journals, I confess to having felt no small amount of regret upon the perusal of Dr. Weber's paper; and I think that both Dr. Kramer and Dr. Weber much underestimate the intelligence and the truth-seeing capacity of British surgeons, to be induced to publish here their observations on Aural Surgery.*

Sarile-row, March, 1866.

$$
\text { ON A CASE }
$$

$$
\text { oF }
$$

\section{POISONING BY HYDROCYANIC ACID.}

By WM. HICKMAN, M.B., F.R.C.S.,

SIRGEON TO TIE WESTERN GENERAL DISPENSART

From the general circumstances surrounding most cases of poisoning, the absence of witnesses capable of noting or appreciating the symptoms, and the uncertainty as to the exact amount of the poison taken, it is but seldom we obtain sufficiently full and accurate details to enable us to make a fair comparison with other cases, so as to answer the important questions so frequently arising-what results may or may not be expected to follow from a given dose?-and what dose may be capable of producing a given set of symptoms? This is more especially the case in poisoning by prussic acid, in which

* This subject is treated at length in "A Vindication of the Present State of Aural Surgery," - to be had gratis at Messrs. Churchill's and other medical publishers. the fatal result is usually so rapidly induced that the cases rarely come under professional (or indeed any) observation until life is completely extinct. It becomes, therefore, the more imperative that any case in which the details have been observed and noted with accuracy should be placed on record; and I have accordingly no hesitation in forwarding for publication in THE LANCET (with the concurrence of my colleague, Mr. Anderson, to whom it naturally belongs) the particulars of a case which occurred at the Western General Dispensary, in which the whole train of symptoms was most carefully observed by the house-surgeon, Mr. R. L. Shone, and in which we were able to ascertain the exact amount of (anhydrous) acid taken.

Mr. Shone's account of the occurrence is as follows:-

"On Sunday morning, whilst sitting in my room on the first-floor, the door suddenly opened, and the porter, W. Ha stout muscular man of forty years, came into the room, put out his hand towards Mr. Killingworth, the assistant who was with me, as if to touch him to enforce his attention, and said, ' Come down directly-I have taken half an ounce of prussic acid.' He then at once turned round and ran quickly down. stairs again to the dispensary-room on the basement. We immediately followed, and found him standing unsupported in the middle of the room. He waved his nand impatiently, and said, "Be quick-give me something:" Some solution of am. monia was given him, followed by sorne tincture of the sesquichloride of iron, both of which he drank, and then, on being told, put his tinger into his throat to endeavour to excite vomiting; this caused one or two slight but abortive efforts, after which he fell suddenly and at once flat down on his back, completely insensible. His face, previously pallid, now became greatly congested, and the veins large and prominent; the eyes tixed, half-closed, and pupils somewhat dilated; no pulse could be felt; the respirations became slow, faint, and gasping, and gradually ceased, whilst a frothy mucus exuded from between the lips; with one or two of the respirations there was a slight stertorous sound. Cold affusion, artiticial respiration, and galvanism were tried, but without any effect, the cold water only causing a slight twitching of the eyebrows and eyelids. Death took place about ten minutes from the time of his coming up to us. Mr. Anderson, who had been sent for, arrived too late to see him alive, but noted the dilated pupils and a glistening appearance of the eyes. In a few hours after death the face regained its natural expression and colour, and it was noticed that it had the hue of health, and perfectly resembled that of one asleep; but after the lapse of a few more hours it again became congested, red, puffed, and ecchymosed, and a reddish fluid appeared at the nostrils.

"Autopsy, thirty hours after death.-Rigor mortis well marked; teeth and lips firmly closed; reddish froth about nostrils and lips; no odour of prussic acid; pupils somewhat dilated and bright. Face swollen; features regular and calm; face, scalp, neck, shoulders, and thighs mottled deep red. Muscles very dark red, giving out much dark fluid blood on division. All the crgans much congested, especially the lungs, kidneys, and the brain and its membranes. Left ventricle of the heart firmly contracted and empty; right-ventricle filled with dark fluid blood; blood everywhere fluid. Stomach partially contracted, containing about two fluid ounces of a brownish, grumous material; mucous membrane markedly reddened all over the larger end, the redness being more de. cided along the rugæ. No odour of prussic acid anywhere about the body, except for one instant whilst the stomach was being divided. In every other respect all the organs were typical of health."

Being present at the post-mortem, I took away the contents of the stomach, and small portions of some of the organs, for chemical examination. The contents smelt strongly of ammonia, but on this being neutralized by nitric acid the odour of prussic acid became very evident, and in a short time pervaded the whole room. On the addition of the acid, also, a large part of the mass became coloured of a deep blue, showing the conversion of a considerable amount of the prussic acid into ferrocyanogen by means of the antidotes employed. Tests were applied in the usual way to the vapour, and abundant evidence of prussic acid was obtained by the production of cyanide of silver, prussian blue, and sulphocyanide of iron, and the whole was afterwards distilled.

This distillate was quantitatively examined for me by $\mathrm{Mr}$. C. Haughton Gill in the laboratory of University College (with the kind permission of Prof. Williamson), and was found to contain at least one grain of anhydrous prussic acid. Mr. Gill was kind enough also to examine for me a specimen of the acid 
from which the poor man had taken it, and found it to contain $1 \cdot 48$ per cent. of real acid.

The small portions of the different organs, not more than three or four ounces altogether, were neglected and exposed for several days ; but even then, on being slightly warmed, the vapour gave unequivocal proof of prussic acid by the characteristic reaction with hydrosulphate of ammonia and perchloride of iron.

In this case there was no doubt the poison was taken accidentally, in mistake for a dose of some medicine (containing tincture of iron and chloric ether) which he had made up for himself, and placed for safety in the cupboard set apart for poisonous drugs, the two bottles being of the same shape and appearance, and only differing slightly in size. The bottle was found replaced and the cupboard door put to, and it would seem that he had poured out his dose into a measure, and.had drunk it off standing at the cupboard; and, finding out his mistake, had put down the measure, and mechanically restoppered and replaced the bottle, closing the cupboard door, and had then run up stairs to the house-surgeon, having on his way to cross the dispensary room, to open a spring door, to go up a crooked flight of fourteen stairs, across a long landing, up a second double flight of eighteen stairs, and a distance of several more paces through two other dours into the housesurgeon's room-that is to say, he twice traversed (in going and returning) a distance of from twenty-five to thirty paces and thirty-two stairs, and was besides able afterwards for several seconds to stand, speak, and assist reasonably in the efforts for his assistance.

It has been generally considered that after a large dose of prussic acid, insensibility must be either almost instantaneous, or immediately following general and violent convulsions; and in many instances grave doubts have arisen as to the character of the death, from the diffculty of believing that the person poisoned can have had time to recork or replace a bottle, to get into bed, or even to pull over the bedclothes; whilst, again, an easy position and placid features have been used as strong evidence that death could not have been occasioned by this acid. A few cases have been recorded, however, proving conclusively that certain series of acts may be gone through after a large dose. Thus Taylor describes the case of a young man who had taken 2.54 grains of anhydrous acid, and had been able to descend thirty steps, walk twenty paces, and open a door; but adds, "there is, I believe, no other instance re corded in which such a series of voluntary acts have been performed, and such a power of locomotion exerted, after so large a dose of the poison has been taken." Christison also mentions a case in which 5 drachms of the Pharmacopoia acid (strength not stated) were taken by a woman whilst in bed, and of whom it was necessary to believe that she had afterwards been able to recork the bottle, lay it down, and pull the bedclothes smoothly over her. He adds the following comment: "I still think that, after swallowing so large a dose, it was impossible that she could have performed all the successive acts of volition mentioned with ordinary deliberation."

Considering the large dose taken, therefore-rather more than 3.5 grains of anhydrous acid ( $\frac{1}{2} \mathrm{oz}$. of an acid containing 1.48 per cent.), - I believe this to be a most remarkable instance of the long retention of conscionsness and voluntary motion, and one likely to become very important in a medicolegal point of view; the possibility, or not, of performing certain acts of consciousness having often the principal bearing in the determination of the question of criminality involved in an inquiry.

The complete absonce of convulsions, in spite, too, of the comparatively protracted mode of death, is at variance with the generally received opinion, and furnishes evidence on a point which has frequently assumed great importance. In this aspect, the appearance of the body noted a few hours after death-it " having the hue of health, and perfectly rosembling one asleep"- has a remarkable interest.

The results of the analyses prove how tenaciously the acid is retained in the structures of the body, and how large a proportion of the quantity taken may be recovered after death, even where no pains have been taken to prevent its dispersion through its volatility. Here, after all the qualitative tests had been applied, and evaporation had been allowed to go on in a warm room, a quantity of acid was recovered from the contents of the stomach equivalent to more than a quarter (sixtyseven minims) of that taken, besides the considerable quantity which still remained in the converted state as prussian blue whilst the organs of the body were also sufficiently saturated to give unequivocal evidence of its presence after many days. the complete absence of odour of prussic acid from the organs and body generally, shows of how little worth this is as negative evidence against the probability of death by even a large dose of the acid. The condition of the stomach is also worth notice as indicative of the irritant action of this poison when in a large dose, and on a comparatively empty stomach.

Dorset-square, March, 1866.

\section{NOTE ON}

\section{LATERAL DEVIATION OF THE EYES IN HEMIPLEGIA AND IN CERTAIN EPILEPTIFORM SEIZURES.}

By J. HUGHLINGS JACKSON, M.D., ASSISTANT-PIIYSICIAN TO THI NATIONAL HOSPITAL FOR MPILEPST AND PARALYSIS, AYD TO THE LONDON HOSPITAL.

IN relating an important case of hemiplegia from injury to the head in THE LANCET of last week, Dr. Humphry mentions that soon after the accident both eyes were turned to the right, whilst the left was the side of the body paralysed. "His livid, pale, expressionless face and helpless condition, with partial loss of consciousness and steady direction of the eyes to the right, indicated a severe shock to the brain and to the body." Lateral deviation of the eyes in hemiplegia is considered by M. E. Bouchut, in an appendix to his recently published work, "Du Diagnostic des Maladies du Système Nerveux par l'Ophthalmoscopie." He says that $M$. Vulpian has observed that in hemiplegia produced by cerebral hæmorrhage or by softening of the brain, there is commonly deviation of the eyes towards the side of the body which is not paralysed. This deviation is, M. Bouchut adds, only temporary. In the case Dr. Humphry relates, he says, "During the first twenty-four hours consciousness was gradually restored, and the movements of both eyes became natural."

I have not yet observed this symptom myself, but I remember hearing Mr. Lockhart Clarke, more than a year ago, in relating a case of hemiplegia, specially draw attention to this peculiarity. Again, Mr. Hutchinson has long observed it as one symptom in the hemiplegia which attends arachnitis over one cerebral hemisphere.

The precise notation of the particular muscles paralysed in the common form of hemiplegia is of much importance, and some differences of opinion may be reconciled by doing this very soon after the attuck, as well as by observing their condition in chronic cases. The cases of hemiplegia which come under my care at the National Hospital for Epilepsy and Paralysis are nearly all cases in which the patient has recovered from the shock of the hiemorrhage or other damage to the nervous system which has produced the symptom. The cases at the London Hospital in which the patient is brought in very soon after the attack are not very numerous, and most of these I do not see very eariy. I think it very likely, then, that I have not seen lateral deviation of the eyes in hemiplegia, simply because $I$ have not begun to study the cases of hemiplegia in which the symptom occurs until after it has passed off.

Partial paralysis of the orbicularis palvebrarum is another symptom very rarely observed in cases of hemiplegia of long duration. I have, however, recorded a case in which it remained weakened when the arm and leg had recovered. Yet, according to some observers, weakness of this muscle is nearly always present at firat. Dr. Todd was so struck by the absence of paralysis of the orbicularis that he even considered the facial nerve was not affected at all, and ascribed the deviation of the face to partial paralysis of the fifth nerve.

Such points, which seem of slight practical importance at first glince, are, I think, of great real importance in helping us to trace the resemblances, and to account for the differences in the particular muscles affected in unilateral paralysis and in unilateral convulsions. I hope to be able to show that, whilst the ordinary form of hemiplegia is generally due to loss of function of the corpus striatum, there are good reasons for considering that in unilateral convulsions the corpus striatum is stimulated. ${ }^{*}$ In one the muscles connected with it are paralysed, and in the other, in action. Now I have seen lateral deviation of the eyes in some of those cases of epileptiform attacks in which one side of the body only has been convulsed; but in the few cases of the hind I have been able to observe

* I use, for the present, the word "stimulated;" but I think that most clinical evidence tends to show that Dr. Radcliffe's riews on the condition of the nervous system in convulsive seizures are more correct than those
generally received. 